Société d'histoire de la révolution de 1848 et des révolutions du XIXe siècle

49 | 2014

1814-1815. Expériences de la discontinuité

\title{
Alejandro Martin RABINOVICH, La société guerrière. Pratiques, discours et valeurs militaires dans le Rio de la Plata (1806-1852)
}

Rennes, Presses universitaires de Rennes, 2013, 348 p. ISBN :

978-2-7535-2792-8. 22 euros.

Walter Bruyère-Ostells

\section{OpenEdition}

Journals

Édition électronique

URL : http://journals.openedition.org/rh19/4801

DOI : 10.4000/rh19.4801

ISSN : $1777-5329$

Éditeur

La Société de 1848

Édition imprimée

Date de publication : 1 décembre 2014

Pagination : 238-240

ISSN : $1265-1354$

Référence électronique

Walter Bruyère-Ostells, "Alejandro Martin RABINOVICH, La société guerrière. Pratiques, discours et valeurs militaires dans le Rio de la Plata (1806-1852) », Revue d'histoire du XIXe siècle [En ligne], 49 | 2014, mis en ligne le 01 décembre 2014, consulté le 22 septembre 2020. URL : http:// journals.openedition.org/rh19/4801 ; DOI : https://doi.org/10.4000/rh19.4801

Ce document a été généré automatiquement le 22 septembre 2020.

Tous droits réservés 


\section{Alejandro Martin RABINOVICH, La société guerrière. Pratiques, discours et valeurs militaires dans le Rio de la Plata (1806-1852)}

Rennes, Presses universitaires de Rennes, 2013, 348 p. ISBN :

978-2-7535-2792-8. 22 euros.

\section{Walter Bruyère-Ostells}

\section{RÉFÉRENCE}

Alejandro Martin RABINOVICH, La société guerrière. Pratiques, discours et valeurs militaires dans le Rio de la Plata (1806-1852), Rennes, Presses universitaires de Rennes, 2013, 348 p. ISBN : 978-2-7535-2792-8. 22 euros.

1 Tirée d'une thèse soutenue à l'ÉHÉSS et qui a reçu le prix d'histoire militaire 2010, l'ouvrage se propose d'examiner les conditions sociales et culturelles dans lesquelles la guerre s'impose au cœur de la vie politique du Rio de la Plata entre 1806, date de la première invasion britannique, et 1852, fin de la Grande Guerre marquée par la défaite de Rosas à Caseros (qui débouche sur l'adoption de la constitution argentine de 1853). Comme l'indique le titre, Alejandro Martin Rabinovitch considère que l'organisation sociale du Rio de la Plata est entièrement subordonnée au contexte des guerres extérieures et intérieures.

Dans la première partie consacrée à « la société guerrière ", le plan est chronologique et reprend la périodisation classique des conflits dans le Rio de la Plata. Malgré la mobilisation d'une abondante littérature scientifique, y compris en sociologie et en science politique, des concepts discutés sont utilisés sans grande précaution au début de la démonstration. Ainsi l'auteur parle-t-il de « militarisation totale qui n'avait guère de précédents » (p. 10). À la page 50, elle est définie comme le principe selon lequel 
"tous les hommes, par le seul fait de naître, étaient tenus de rendre un service militaire ». L'hypothèse de "militarisation totale » d'une société sur ce seul critère paraît excessive. Par ailleurs, à force de vouloir trop démonter, on affaiblit son argumentation. Y a-t-il une réelle différence entre une mobilisation de $12,7 \%$ des hommes au Rio de la Plata en 1818 et «la France de la levée en masse, en pleine révolution qui n'arrivait qu'à un homme sur neuf » (soit 11,1\%)? Encore faudrait-il préciser que le taux est de 18,6\% pour les années 1799 à 1803 et atteint $30 \%$ entre 1805 et $1814^{1}$. L'auteur évoque la «brutalisation » des hommes du Rio de La Plata (p. 71) sans discuter le concept ou rappeler qu'il est l'objet de controverses pour le XIX ${ }^{e}$ siècle comme pour le $\mathrm{XX}^{\mathrm{e}}$. Par ailleurs, la démonstration souffre ici ou là d'un manque de comparatisme avec des situations sur le Vieux Continent. Les développements sur la place des femmes, notamment le système des rabonas dans l'Armée des Andes, appuient la démonstration. Toutefois, les exemples de femmes combattantes sont présentées, là encore, comme une exception sud-américaine. Une comparaison avec la guerre d'indépendance grecque par exemple (figure de la Bouboulina) aurait permis de nuancer le propos.

3 L'analyse est, en revanche, très convaincante quand l'auteur déconstruit les catégories de troupes régulières et irrégulières pour mettre en lumière une déclinaison de types de combattants et un poids significatif des diverses forces irrégulières dans les combats en ligne. La grande qualité de l'ouvrage repose sur cette analyse très fine des catégories et des jeux d'acteurs. Dans le chapitre 3 (intitulé «Fragmentation 1820-1852»), la logique des affrontements entre caudillos et les rapports fluctuants avec les Indiens permet de comprendre la complexité des confrontations d'intérêts, au-delà du seul antagonisme habituellement décrit entre pouvoir central et provinces. Cette question indienne permet ainsi de mesurer les rythmes de cette situation de crises de 1806 à 1852. Tantôt, certains acteurs cherchent l'alliance des Indiens quand la situation interne est tendue et tantôt, ils portent la guerre avec violence contre ces mêmes Indiens quand le calme revient entre les provinces et le pouvoir central.

4 La deuxième partie a ensuite pour objet de montrer comment fonctionnent les différentes «forces de guerre ». Pour chacune d'elle, il s'agit d'éclairer l'articulation entre type de mobilisation, degré de régularité de la troupe, pratiques guerrières et cohésion au combat. L'approche culturelle, notamment avec le rapport aux armes employées (couteau et baïonnette notamment), est ici privilégiée. Les transferts de doctrines militaires (écrits de Guibert et/ou règlements français) mais aussi leur nécessaire hybridation pour répondre au théâtre du Rio de la Plata, permettent ensuite de monter le drill de chacune de ces «forces de guerre ». Les circulations de militaires entre Europe et Rio de la Plata sont mentionnées sans toutefois être réellement prises en compte. Dans la phase préparatoire mais encore davantage lors du combat luimême, on mesure l'importance des acteurs intermédiaires, à l'instar du petit capitaine ou petit caudillo, dont le rôle est essentiel pour comprendre les processus de mobilisation et de résilience (cohésion) des groupes combattants.

5 La troisième partie est consacrée au seul combat. L'auteur revient sur le poids des forces intermittentes (montoneras notamment) dans les campagnes du Rio de la Plata. Sans que cela soit dit ainsi, l'hybridation entre bataille à l'européenne, pratiques des gauchos et des Indiens est analysée dans le détail : «l'art de la guerre évolua vers un modèle plus simple et plus efficace, fondé sur les milices de cavalerie» (p. 303). Plus encore qu'en Europe, il n'y a pas de choc brutal de deux masses d'infanterie, ce qui 
rétablit une égalité de chance au combat sur champ libre entre troupe régulière et autres "forces de guerre». Alejandro M. Rabinovich en conclut que la bataille ne permet pas à la ligne de venir à bout des forces intermittentes dans les crises qui agitent le Rio de la Plata. C'est donc à la lumière de la seconde et de la troisième partie que l'on comprend mieux le processus de fragmentation décrit précédemment et l'échec du projet unitaire porté par l'État central.

\section{NOTES}

1. Cf. André Corvisier [dir.], Histoire militaire de la France, tome 2, Paris, Presses universitaires de France, 1994. 